\title{
Acute liver injury and anorexia nervosa: a case report
}

\author{
Simona Pascolini, ${ }^{1,2}$ Michele Cevolani, ${ }^{1,2}$ Federico Lari, ${ }^{3}$ Luigi Muratori, ${ }^{1,2}$ Marco Lenzi ${ }^{1,2}$ \\ ${ }^{1}$ Department of Medical and Surgical Sciences, Bologna University; ${ }^{2}$ Internal Medicine Area of Emergency Department, \\ Sant'Orsola-Malpighi Hospital, Bologna; ${ }^{3}$ Department of Internal Medicine, Hospital of San Giovanni in Persiceto (BO), Italy
}

\begin{abstract}
Anorexia nervosa is an eating disorder characterized by restriction of energy intake leading to a significant decrease in body weight. While it is primarily a psychiatric disorder, numerous medical complications can occur. In this article we describe a case of a 25-year-old woman with a 12-year history of severe restrictive anorexia nervosa that was referred to the Emergency Service of our Hospital, transferred from a psychiatric institute, for severe weight loss, dehydration, and progressive increase in transaminases. During the hospital stay she developed an acute liver injury with an increase in transaminase level up to $40 \times$ the ULN. Infective and immunological causes of acute hepatitis were excluded. In the suspect of severe starvation acute liver injury, we performed a nutritional assessment and started parenteral nutrition. After 15 days of parenteral nutrition, she gained $2.5 \mathrm{~kg}$ of body weight and liver tests were drastically reduced and nearly normal.
\end{abstract}

\section{Introduction}

Anorexia nervosa (AN) is an eating disorder characterized by restriction of energy intake leading to a significant decrease in body weight, intense fear of gaining weight or getting fat, disturbance in the way body weight or shape is experienced..$^{1}$ Although it is primarily considered a psychiatric disorder, several medical complications can occur, including electrolyte disorders, cardiovascular problems, endocrine disorders, osteoporosis, and gastrointestinal manifestations. ${ }^{2}$ Achalasia, gastroesophageal reflux, alteration of gastric motility, liver abnormalities, im-

Correspondence: Michele Cevolani, Internal Medicine Area of Emergency Department, Sant'Orsola-Malpighi Hospital, via Albertoni 2, Pad. 5, 40138 Bologna, Italy.

Tel.: +39.051.2145224 - Fax: +39.051.2144836.

E-mail: michele.cevolani2@gmail.com

Key words: Anorexia nervosa; malnutrition; acute liver injury; elevated liver enzymes.

Contributions: the authors contributed equally.

Conflict of interests: the authors declare no conflict of interests.

Received for publication: 15 January 2019.

Accepted for publication: 26 February 2019.

This work is licensed under a Creative Commons Attribution NonCommercial 4.0 License (CC BY-NC 4.0).

CCopyright S. Pascolini et al., 2019

Licensee PAGEPress, Italy

Italian Journal of Medicine 2019; 13:128-131

doi:10.4081/itjm.2019.1135 paired coagulation, pancreatic injury, superior mesenteric artery syndrome and rectal prolapse are the most common gastrointestinal complications. ${ }^{3}$ Alteration of liver enzymes is quite commonly observed in this setting, and a number of case reports have described transaminase elevation in patients with AN. ${ }^{4-11}$ Nagata et al. reported in anorexic patients aged 10-22 years old $(n=356)$ a $37.0 \%$ prevalence of aspartate transaminase (ALT) $>40 \mathrm{IU} / \mathrm{L}$ on admission, while the prevalence of ALT> $>80 \mathrm{IU} / \mathrm{L}$ was $6.2 \% .^{12}$ Rosen et al. reported in older patients (22-36 yo, $\mathrm{n}=181)$ a $35.4 \%$ prevalence of alanine transaminase $(\mathrm{AST})>120 \mathrm{IU} / \mathrm{L}$ or ALT $>135 \mathrm{IU} / \mathrm{L} .{ }^{13}$

\section{Case Report}

DL, a 25-year-old woman with a 12-year history of severe restrictive AN, was referred to the Emergency Service of our Hospital, transferred from a psychiatric institute, for severe weight loss, dehydration, progressive increase in transaminases (AST $513 \mathrm{IU} / \mathrm{L}$, ALT $559 \mathrm{IU} / \mathrm{L})$ and hyponatremia $(128 \mathrm{mEq} / \mathrm{L})$. Upon admission, body weight was $22.5 \mathrm{~kg}$ [height $1.51 \mathrm{~m}$, body mass index (BMI) 9.9]. Blood pressure (BP) was $55 / 40 \mathrm{mmHg}$ and she presented with severe bradycardia (heart rate $35 / \mathrm{min}$ ). The patient complained of abdominal discomfort and confusion. General examination showed severe cachexia, dehydration, acrocyanosis; thoracic, abdominal and neurological examinations were normal. Blood tests showed: white blood cells count $4640 / \mathrm{mmc}$, hemoglobin $14.3 \mathrm{~g} / \mathrm{dL}$, platelets $174,000 / \mathrm{mmc}$, international normalized ratio (INR) 1.26 , glucose $39 \mathrm{mg} / \mathrm{dL}$, sodium $122 \mathrm{mmol} / \mathrm{L}$, potassium $4.3 \mathrm{mmol} / \mathrm{L}$, albumin $5.2 \mathrm{~g} / \mathrm{dL}$, AST $735 / 35$ IU/L, ALT 857/35 IU/L, creatine phosphokinase 443/170 IU/L, C-reactive protein $0.02 \mathrm{mg} / \mathrm{dL}$. 
The patient was admitted to our Internal Medicine Unit, where we immediately started rehydration therapy to correct severe dehydration and electrolyte imbalance. During the first days, the patient was extremely noncompliant with the therapeutic proposals (she refused i.v. liquids and the minimum caloric intake). Psychiatric therapy was implemented with olanzapine $5 \mathrm{mg}$ p.o./die, sertraline $25 \mathrm{mg}$ p.o./die and clonazepam $1 \mathrm{mg}$ p.o./tid. On $4^{\text {th }}$ day of hospitalization, after the development of progressive blurred speech and loss of consciousness, severe hypoglycemia $(13 \mathrm{mg} / \mathrm{dL})$ was documented and successfully treated with $10 \%$ glucose i.v. solution. However, liver enzymes continued to increase and on day 6 AST and ALT rose to $3658 \mathrm{IU} / \mathrm{L}$ and $3553 \mathrm{IU} / \mathrm{L}$, respectively; INR was 1.57 ; infective and immunological causes of acute hepatitis were excluded (Table 1). In the suspect of severe starvation acute liver injury, we performed a nutritional assessment (BMI 9.21 - weight $21 \mathrm{~kg}$ - basal energy expenditure $804 \mathrm{Kcal} /$ day, total energy expenditure 964 $\mathrm{Kcal} /$ day) and proposed parenteral nutrition; after discussion with the patient, her family, her psychiatrist and psychologist, she finally accepted. On day 7, parenteral nutrition was started, with an overall intake of 400 daily Kcalories to avoid refeeding syndrome ${ }^{14-16}$ (see formulation A - Table 2) distributed during $12 \mathrm{~h}$ of continuous infusion and administered via a central venous catheter. On day 14 the caloric intake was raised to $600 \mathrm{Kcal} / \mathrm{die}$ (see Formulation B - Table 2). Liver function tests immediately began to improve, and serial controls showed normalization of INR and sodium levels (Table 3 and Figure 1).

After some days of acceptable compliance and adherence to the nutritional treatment, the patient became agitated, showing anxiety and suspicious behavior towards her parents and the Hospital staff.

On day 22 , she developed fever (up to $39.5^{\circ} \mathrm{C}$ ); blood cultures were taken, empirical antibiotic therapy (ceftriaxone i.v. $1 \mathrm{~g} / \mathrm{die}$ ) was started and, in the suspect of a central venous device infection, parenteral nutrition was discontinued. Blood cultures resulted positive for Candida albicans, therefore antifungal therapy (caspofungin $50 \mathrm{mg}$ i.v./die) was initiated. After excluding thrombosis of the jugular vein, the central device was removed.

Antimycotic therapy was rapidly effective and in $48 \mathrm{~h}$ the patient was afebrile; we repeated blood cultures, which resulted negative. The patient refused any additional proposal of nutrition and asked to be discharged. After 26 days of hospitalization and 14 of parenteral nutrition, she gained $2.5 \mathrm{~kg}$ of body weight (BMI 11.0), liver tests were drastically reduced and nearly normal (AST 78 IU/L, ALT 150 $\mathrm{IU} / \mathrm{L}$ ), electrolytes were normal (sodium $136 \mathrm{mmol} / \mathrm{l}$, potassium $3.8 \mathrm{mmol} / \mathrm{L}$ ), BP was $85 / 55 \mathrm{mmHg}$, heart rate $70 / \mathrm{min}$.
In agreement with the Psychiatrist, the patient was discharged and subsequently followed up by the psychiatric territorial service.

Table 1. Tests performed in order to rule out other causes of acute liver injury in the patient.

\begin{tabular}{lc}
\hline Test performed & Result \\
\hline ANA & neg \\
\hline IgA anti-transglutaminase & neg \\
\hline IgG anti deaminated gliadin peptides & neg \\
\hline Liver Immunoblot & neg \\
\hline Ceruloplasmin & $21 \mathrm{mg} / \mathrm{dL}$ \\
\hline Anti CMV IgG & pos \\
\hline Anti CMV IgM & neg \\
\hline Anti EBV IgG & pos \\
\hline Anti EBV IgM & neg \\
\hline Anti HAV IgM & neg \\
\hline HBsAg & neg \\
\hline Anti HBc & neg \\
\hline Anti HCV & neg \\
\hline
\end{tabular}

ANA, anti-nuclear antibody; IgA, IgG, IgM, immunoglobulin A, G, and M; CMV, cytomegalovirus; EBV, Epstein-Barr virus; $\mathrm{HAV}, \mathrm{HCV}$, hepatitis $\mathrm{A}$ and $\mathrm{C}$ viruses.

Table 2. The two different formulations administered to the patient, provided by a nutrition consultant.

\begin{tabular}{|c|c|c|}
\hline Fol & mulation A & Formulation B \\
\hline Volume & 1000 & 1000 \\
\hline Total kilocalories & 400 & 600 \\
\hline g glucose & 30 & 28 \\
\hline g lipids (as fish oil) & 20 & 35 \\
\hline $\mathrm{g}$ amino acids & 20 & 26 \\
\hline Sodium (mEq) & 30 & 40 \\
\hline Calcium (mEq) & 5 & 5 \\
\hline Potassium (mEq) & 20 & 20 \\
\hline Magnesium (mEq) & 6 & 7 \\
\hline Chlorine (mEq) & 30 & 40 \\
\hline Phosphate (mEq) & 20 & 20 \\
\hline Mixture of trace elements $(\mathrm{mL})^{*}$ & 5 & 5 \\
\hline Multivitamin preparation (vial) ${ }^{\circ}$ & $1 \mathrm{fL}$ & $1 \mathrm{fL}$ \\
\hline \multicolumn{3}{|c|}{$\begin{array}{l}* 1 \mathrm{~mL} \text { of trace elements contained: chromic chloride } 6 \mathrm{H}_{2} \mathrm{O} 5.33 \mu \mathrm{g} \text {, copper chloride } \\
2 \mathrm{H} \mathrm{H}_{2} \mathrm{O} 0.34 \mathrm{mg} \text { ferric chloride } 6 \mathrm{H}_{2} \mathrm{O} 0.54 \mathrm{mg} \text {, manganese chloride } 4 \mathrm{H}_{2} \mathrm{O} 99.0 \mu \mathrm{g} \text {, } \\
\text { potassium iodide } 16.6 \mu \mathrm{g} \text { sodium fluoride } 0.21 \mathrm{mg} \text {, sodium molybdate } 2 \mathrm{H}_{2} \mathrm{O} 4.85 \\
\mu \mathrm{g} \text {, sodium selenite anhydrous } 6.90 \mu \mathrm{g} \text { zinc chloride } 1.36 \mathrm{mg} \text {; }{ }^{\circ} 1 \mathrm{vial} \text { of multivitamin } \\
\text { preparation contained: retinol palmitate corresponding to retinol (vitamin A) } 3500 \mathrm{IU} \text {, } \\
\text { cholecalciferol (vitamin D3) } 200 \mathrm{IU} \text {, DL } \alpha \text {-tocopherol } 10.2 \mathrm{mg} \text { corresponding to } \alpha \text { - } \\
\text { tocopherol (vitamin E) } 11.2 \mathrm{IU} \text {, ascorbic acid (vitamin C) } 125 \mathrm{mg} \text {, nicotinamide (vi- } \\
\text { tamin B3) } 46 \mathrm{mg} \text {, dexpanthenol } 16.15 \mathrm{mg} \text { corresponding to pantothenic acid (vitamin } \\
\text { B5) } 17.25 \mathrm{mg} \text {, pyridoxine hydrochloride } 5.5 \mathrm{mg} \text { corresponding to pyridoxine (vitamin } \\
\text { B6) } 4.53 \mathrm{mg} \text {, riboflavin sodium phosphate } 5.67 \mathrm{mg} \text { corresponding to riboflavin (vit- } \\
\text { amin B2) } 4.14 \mathrm{mg} \text {, cocarboxylase tetrahydrate } 5.8 \mathrm{mg} \text { corresponding to thiamine (vi- } \\
\text { tamin B1) } 3.51 \mathrm{mg} \text {, folic acid } 414 \mathrm{mcg} \text {, D-biotin } 60 \mathrm{mcg} \text {, cyanocobalamin (vitamin } \\
\text { B12) } 5.5 \mathrm{mcg} \text {. }\end{array}$} \\
\hline
\end{tabular}




\section{Discussion and Conclusions}

AN is a well-known psychiatric disorder associated with a variety of medical complications, including electrolyte disorders, cardiovascular problems, endocrine disorders, osteoporosis and gastrointestinal manifestations. $^{2}$

Mild to moderate hypertransaminasemia in AN has been reported ${ }^{4-9}$ and appeared to be associated with hepatic steatosis induced by an imbalance between hepatic triglyceride synthesis and decrease in lipoprotein synthesis, due to decreased amino acid availability; in most cases, it resolves with nutritional improvements: ${ }^{17}$ marked elevation of transaminase levels, jaundice and coagulopathy, as seen in our case, are a much rarer presentation of acute liver injury associated with AN.

The pathological mechanisms involved remain unclear; some authors have suggested that hepatic hypoperfusion (ischemic hepatitis) could be the main pathogenetic mechanism involved in acute liver injury in AN. ${ }^{18,19}$ On the other hand, Ratou and his colleagues have questioned this hypothesis by examining liver biopsies from 12 patients with acute hepatic injury due to anorexia nervosa. ${ }^{17}$ None of the biopsies showed hallmarks of ischemic injury, and the Authors supposed starvation-induced hepatocyte autophagy to be the main pathogenetic mechanism. In a recent case report, Massoud and Crowe described the case of a 24year-old man with markedly elevated transaminases, jaundice and coagulopathy; ${ }^{20}$ in this case, AST and

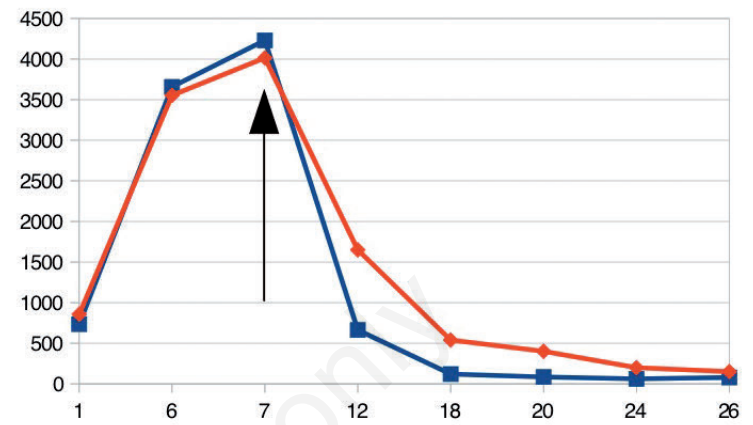

Figure 1. Transaminase trend. The arrow points start of intravenous nutrition.

Table 3. Biochemical findings and trends.

\begin{tabular}{|c|c|c|c|c|c|c|c|c|}
\hline & Admission & Day 6 & Day 7 & Day 12 & Day 18 & Day 20 & Day 24 & Discharge \\
\hline WBC $10^{9} / \mathrm{L}$ & 4.64 & 3.17 & 3.68 & 2.06 & 1.67 & 1.7 & 4.79 & \\
\hline N\% - L\% & $51-44$ & $45-50$ & & $50-41$ & $47-37$ & $63-25$ & $57-32$ & \\
\hline $\mathrm{Hb}(\mathrm{MCV}) \mathrm{g} / \mathrm{dL}(\mathrm{fL})$ & $14.3(87)$ & $13.20(85)$ & $13.9(87)$ & $10.1(89)$ & $8.6(89)$ & $9(89)$ & $8.9(88)$ & \\
\hline Hct $\%$ & 39.7 & 35.4 & 38.7 & 28.4 & 24.8 & 25 & 30.9 & \\
\hline PLT $10^{9} / \mathrm{L}$ & 174 & 73 & 55 & 39 & 86 & 115 & 176 & \\
\hline INR-aPTT & $1.27-1.32$ & 1.57 & 1.42 & 1.03 & & & & \\
\hline Glucose mg/dL & 39 & & & 141 & & 81 & 69 & \\
\hline Creatinine mg/dL & 0.52 & 0.5 & 0.54 & 0.36 & 0.3 & & 0.34 & 0.26 \\
\hline $\mathrm{Na} \mathrm{mmol} / \mathrm{L}$ & 122 & 127 & 124 & 132 & 136 & 134 & 122 & 136 \\
\hline $\mathrm{K}$ mmol/L & 4.3 & 3.9 & 4.3 & 4,3 & 3.6 & 3.8 & 4 & 3.8 \\
\hline $\mathrm{Cl} \mathrm{mmol} / \mathrm{L}$ & & & 92 & 95 & 101 & & 88 & 103 \\
\hline $\mathrm{Ca} \mathrm{mg} / \mathrm{dL}$ & 9.6 & & 8.2 & 8.6 & 8.1 & 8.4 & 8.1 & 7.1 \\
\hline $\mathrm{P} \mathrm{mg} / \mathrm{dL}$ & & & 2.1 & 3.6 & 1.8 & 3.7 & 3 & 4.5 \\
\hline $\mathrm{Mg} \mathrm{mg} / \mathrm{dL}$ & 2.3 & & 1.8 & 1.7 & & 1.9 & 1.6 & 1.5 \\
\hline Albumin g/dL & 5.2 & & 4.2 & & 3.18 & 3.5 & & \\
\hline Bilirubin tot./direct mg/dL & $1.90 / 0.46$ & & $1.48 / 0.35$ & $0.53 / 0.13$ & $0.44 / 0.1$ & & & \\
\hline AST IU/L & 735 & 3658 & 4231 & 663 & 120 & 84 & 61 & 78 \\
\hline ALT IU/L & 857 & 3553 & 4015 & 1650 & 539 & 401 & 199 & 150 \\
\hline GGT IU/L & & & & 163 & 125 & 119 & 114 & 95 \\
\hline ALP IU/L & & & & 279 & 177 & 180 & 146 & 147 \\
\hline
\end{tabular}

WBC, white blood cells count; Hb, hemoglobin; MCV, mean corpuscular volume; Hct, hematocrit; PLT, platelets; INR, international normalized ratio; aPTT, activated partial thromboplastin time; $\mathrm{Na}$, sodium; K, potassium; $\mathrm{Cl}$, chlorum; P, phosphorus; Mg, magnesium; AST, aspartate transaminase; ALT, alanine transaminase; GGT, gamma-glutamyl transpeptidase; ALP, alkaline phosphatase. 
ALT values reached a peak of $2033 \mathrm{IU} / \mathrm{mL}$ and 1410 $\mathrm{IU} / \mathrm{mL}$ respectively (up to $40 \times$ the ULN), and completely returned to normal levels after proper nutrition; they managed to get a liver biopsy that excluded ischemic hepatitis; surprisingly, the histological changes they found were minimal in contrast with the marked elevation of transaminases.

We could not perform a liver biopsy because of the poor compliance of our patient; however, we still believe that our case is peculiar, as it is the only case described with such a marked elevation of transaminases (up to $120 \times$ the ULN); moreover, hypertransaminasemia almost normalized after only 14 days of proper nutrition.

This case report demonstrates that AN can cause acute life-threatening medical conditions, such as the acute liver injury we described, for which pathogenesis is still largely unclear. What is clear is that these conditions need a rapid recognition and a multidisciplinary approach (involving Psychiatrist-NutritionistInternist) to initiate as soon as possible a proper treatment, in order to improve the otherwise poor prognosis of these fragile patients.

\section{References}

1. American Psychiatric Association. Diagnostic and statistical manual of mental disorders, 5th Ed. Arlington, VA: American Psychiatric Association; 2013.

2. Mehler PS, Brown C. Anorexia nervosa - medical complication. Int J Eating Disord 2015;3:11.

3. Norris ML, Harrison ME, Isserlin L, et al. Gastrointestinal complication associated with anorexia nervosa: a systematic review. Int J Eating Disord 2016;49:216-37.

4. Giordano F, Arnone S, Santeusanio F, Pampanelli S. Brief elevation of hepatic enzymes due to liver ischemia in anorexia nervosa. Eat Weight Disord 2010;15:e294-7.

5. Dowman J, Arulraj R, Chesner I. Recurrent acute hepatic dysfunction insevere anorexia nervosa. Int $\mathrm{J}$ Eat Disord 2010;43:770-2.

6. Sakurai-Chin C, Ito N, Taguchi M, et al. Hypoglycemic coma in a patient with anorexia nervosa coincident with acute exacerbation of liver injury induced by oral intake of nutrients. Intern Med 2010;49:1553-6.
7. De Caprio C, Alfano A, Senatore I, et al. Severe acute liver damage in anorexia nervosa: two case reports. Nutrition 2006;22:572-5.

8. Furuta S, Ozawa Y, Maejima K, et al. Anorexia nervosa with severe liver dysfunction and subsequent critical complications. Intern Med 1999;38:575-9.

9. Narayanan V, Gaudiani JL, Harris RH, Mehler PS. Liver function test abnormalities in anorexia nervosa-cause or effect. Int J Eat Disord 2010;43:378-81.

10. Hanachi M, Melchior JC, Crenn P. Hypertransaminasemia in severely malnourished adult anorexia nervosa patients: risk factors and evolution under enteral nutrition. Clin Nutr 2013;32:391-5.

11. Bridet L, Martin JJ, Nuno JL. Acute liver damage and anorexia nervosa: a case report. Turk J Gastroenterol 2014;25:205-8.

12. Nagata JM, Park KT, Colditz K, Golden NH. Associations of elevated liver enzymes among hospitalized adolescents with anorexia nervosa. J Pediatr 2015;166:439-43.

13. Rosen E, Sabel AL, Brinton JB, et al. Liver dysfunction in patients with severe anorexia nervosa. Int $\mathrm{J}$ Eating Disord 2016;49:151-8.

14. Mehanna HM, Moledina J, Travis J. Refeeding syndrome: what it is, and how to prevent and treat it. BMJ 2008;336:1495-8.

15. Stanga Z, Brunner A, Leuenberger M, et al. Nutrition in clinical practice - the refeeding syndrome: illustrative cases and guidelines for prevention and treatment. Eur J Clin Nutr 2008;62:687-94.

16. National Institute for Health and Care Excellence (NICE). Nutrition support for adults: oral nutrition support, enteral tube feeding and parenteral nutrition. Clinical guideline [CG32]; last updated: August 2017. Available from: https://www.nice.org.uk/guidance/cg32 Accessed: February 2018.

17. Rautou PE, Cazals-Hatem D, Moreau R, et al. Acute liver cell damage in patients with anorexia nervosa: a possible role of starvation-induced hepatocyte autophagy. Gastroenterology 2008;135:840-8.

18. Di Pascoli L, Lion A, Milazzo D, Caregaro L. Acute liver damage in anorexia nervosa. Int $\mathrm{J}$ Eat Disord 2004;36:114-7.

19. De Caprio C, Alfano A, Senatore I, et al. Severe acute liver damage in anorexia nervosa: two case reports. Nutrition 2006;22:572-5.

20. Massoud O, Crowe R. Acute liver injury associated with anorexia nervosa. J Gastroenterol Hepatol Res 2017;6: 2498-501. 